\title{
Estimação da fração digestível da proteína bruta em dietas para bovinos em condições brasileiras
}

\author{
Edenio Detmann ${ }^{1}$, Douglas dos Santos Pina ${ }^{2}$, Sebastião de Campos Valadares Filho', José \\ Maurício de Souza Campos ${ }^{1}$, Mário Fonseca Paulino1, André Soares de Oliveira ${ }^{2}$, Polyana \\ Albino Silva ${ }^{2}$, Lara Toledo Henriques ${ }^{3}$
}

\author{
${ }^{1}$ Departamento de Zootecnia, Universidade Federal de Viçosa, Viçosa-MG, 36571-000, Bolsista do CNPq \\ 2 Doutorando em Zootecnia - UFV. Bolsista do CNPq. \\ 3 Pós-Doutoranda, DZO-UFV. Bolsista da CAPES.
}

RESUMO - Objetivou-se neste estudo propor e validar um modelo para estimação da fração aparentemente digestível da proteína bruta (PB) de dietas fornecidas a bovinos. As bases teóricas para o desenvolvimento do modelo fundamentaram-se no coeficiente de digestibilidade verdadeiro e na contribuição metabólica fecal. O método de estimação destes parâmetros baseou-se no teste de entidade nutricional. O banco de dados utilizado para construção do modelo foi constituído de 39 e 54 médias experimentais para vacas em lactação (dez experimentos) e bovinos em crescimento e terminação (23 experimentos). Adotou-se o esquema de identidade de modelos por variável Dummy para diferenciação entre categorias animais. O banco de dados utilizado para validação do modelo proposto foi obtido de quatro experimentos, dois para cada categoria animal. O coeficiente de digestibilidade verdadeiro da PB, cuja estimativa foi de 0,7845 , não diferiu entre as categorias animais. A fração metabólica fecal foi superior para vacas em lactação e mostrou-se não relacionada ao teor dietético de PB (PB\%) quando expressa como percentual desta quantidade. Assim, para animais alimentados ad libitum, o teor de PB aparentemente digestível $\left(\mathrm{PB}_{\mathrm{ad}} \%\right)$ pode ser estimado pelas equações: $\mathrm{PB}_{\mathrm{ad}} \%=0,7845 \mathrm{~PB} \%$ - 0,97, para vacas em lactação; e $\mathrm{PB}_{\mathrm{ad}} \%=0,7845 \mathrm{~PB} \%$ - 1,61, para bovinos em crescimento e terminação. O processo de validação indicou similaridade entre valores preditos e observados de $\mathrm{PB}_{\mathrm{ad}} \%$. Os modelos propostos poderão ampliar a acurácia de predição do teor de NDT utilizando-se a composição química da dieta.

Palavras-chave: equações somativas, digestibilidade aparente, teste de entidade nutricional, sistema NRC

\section{Estimation of crude protein digestible fraction in cattle diets under Brazilian conditions}

\begin{abstract}
The objective of this study was to propose and validate a model to estimate the apparently digestible fraction of crude protein (CP) of cattle diets. The theoretical framework for model development was based on true digestibility coefficient and metabolic fecal contribution. The estimation of both parameters was done by using the Lucas test. The dataset for model building was composed by 39 and 54 means from 10 experiments with lactating cows and 23 experiments with growing and finishing cattle, respectively. For comparisons of animal categories a Dummy variable was used. The dataset for model validation came from two trials with lactating cows and two trials with growing and finishing cattle. The true digestibility coefficient, which was estimated as 0.7845 did not differ among animal categories. The greatest metabolic fecal CP was observed on lactating cows but it was not affected by dietary CP level when expressed as percentage of dietary CP. Thus, for animals fed ad libitum the content of apparently digestible $\mathrm{CP}\left(\mathrm{CP}_{\mathrm{ad}} \%\right)$ in the diet can be estimated by the following equations: $\mathrm{CP}_{\mathrm{ad}} \%=0.7845 \mathrm{CP} \%-0.97$ for lactating cows and $\mathrm{CP}_{\mathrm{ad}} \%=0.7845 \mathrm{CP} \%-1.61$ for growing and finishing cattle. The validation procedure indicated no differences between observed and estimated values of $\mathrm{CP}_{\mathrm{ad}} \%$. It can be concluded that the proposed models will improve the accuracy of TDN prediction using the chemical composition of the diet.
\end{abstract}

Key Words: apparent digestibility, Lucas test, NRC system, summative equations

\section{Introdução}

A estimação dos parâmetros de digestibilidade dos alimentos constitui aspecto preponderante para quantificação de seu teor energético, notadamente via nutrientes digestíveis totais, permitindo o balanceamento adequado de dietas que propiciem o atendimento das demandas para mantença e produção dos animais.

No entanto, mesmo constituindo um parâmetro digestivo estático, ou seja, que pode ser representado por uma 
estimativa pontual, a estimação da digestibilidade de um alimento ou de seus respectivos componentes químicos constitui processo oneroso e com elevada demanda de tempo para obtenção de estimativas quando realizado pelos métodos clássicos in vivo.

Embora métodos alternativos para estimação de parâmetros da digestibilidade tenham sido desenvolvidos em ambientes in situ ou in vitro, tanto por vias gravimétricas (Tilley \& Terry, 1963) quanto metabólicas (Schofield et al., 1994), as estimativas obtidas têm apresentado vícios substanciais em relação aos valores observados in vivo para alimentos produzidos em condições tropicais (Vieira et al., 2000; Detmann et al., 2005a).

De forma alternativa aos métodos biológicos, a utilização da composição química dos alimentos como método de predição da digestibilidade em ruminantes tem sido sugerida por diversos autores (Conrad et al., 1984; Weiss et al., 1992; Van Soest, 1994). Diante dessa perspectiva, o NRC (2001) propôs a adoção de um método com esse embasamento para estimação do teor de NDT dos alimentos, o qual consiste em um sistema de equações somativas em que, a cada grupo de compostos químicos, destina-se uma equação para obtenção de estimativas das frações verdadeiramente digestíveis, com posteriores correções para perdas metabólicas e nível de consumo.

Contudo, embora seja um sistema teoricamente embasado (Conrad et al., 1984; Weiss et al., 1992), esse método tem apresentado eficiência de predição não satisfatória quando aplicado a alimentos obtidos em condições tropicais (Rocha Jr. et al., 2003; Campos, 2004; Detmann et al., 2004a; Oliveira, 2005), tornando as estimativas obtidas substancialmente desviadas dos valores observados in vivo.

De forma mais específica, por se tratar de um sistema somativo (Weiss et al., 1992; NRC, 2001), as divergências das estimativas de NDT constituem somatório simples das divergências observadas para cada grupo de compostos separadamente (EE, FDN, CNF e PB). Desta forma, possíveis correções ou alterações sobre o sistema somativo adotado pelo NRC (2001) devem ser investigadas quanto às estimativas individuais de cada grupo de compostos, as quais refletirão diretamente sobre a exatidão das estimativas obtidas para o nível de NDT do alimento ou da dieta.

Entre os grupos de compostos orgânicos dos alimentos fornecidos para bovinos, as estimativas dos teores de $\mathrm{PB}$ digestível obtidas via sistema de equações somativas (NRC, 2001) têm contribuído para a falta de exatidão das estimativas de NDT em condições tropicais, sendo comumente inferiores aos valores observados in vivo (Rocha Jr. et al., 2003; Campos, 2004; Oliveira, 2005; Pina, 2005).
Segundo proposições de Lucas \& Smart (1959), as estimativas de digestibilidade aparente dos componentes dos alimentos com comportamento digestivo homogêneo, entre os quais se destacam o EE e a PB, poderiam ser obtidas a partir de seu coeficiente de digestibilidade verdadeiro e de sua contribuição metabólica fecal. Esse processo de estimação passou a ser denominado teste de entidade nutricional (Lucas \& Smart, 1959; Van Soest, 1994) e apresenta potencial ainda pouco conhecido em condições tropicais, podendo constituir alternativa para construção de modelo de maior acurácia para estimação da digestibilidade utilizando-se os teores dietéticos.

Desta forma, objetivou-se neste estudo desenvolver e validar um modelo para estimação da fração aparentemente digestível da PB a partir de sua concentração dietética em animais alimentados em condições tropicais com base no coeficiente de digestibilidade verdadeiro e na contribuição metabólica fecal.

\section{Material e Métodos}

O banco de dados utilizado na construção do modelo foi constituído pelas médias de tratamentos obtidas em 13 experimentos conduzidos com bovinos em crescimento e terminação (Carvalho et al., 1997; Valadares et al., 1997; Ladeira et al., 1999; Cardoso et al., 2000; Dias et al., 2000; Tibo et al., 2000; Véras et al., 2000; Leão, 2002; Ítavo et al., 2002; Magalhães, 2003; Rennó, 2003; Chizzotti et al., 2005; Costa et al., 2005) e dez com vacas em lactação (Malafaia et al., 1996a, b; Mora et al., 1996a, b; Oliveira et al., 2001; Silva et al., 2001; Assis et al., 2004a; 2004b; Chizzotti, 2004; Mendonça et al., 2004; Soares et al., 2004; Pereira et al., 2005).

Foram levantadas informações relativas ao teor dietético (\% da MS), ao consumo (g/dia) e à digestibilidade aparente total (\%) da PB. Em todos os experimentos avaliados, os animais foram alimentados ad libitum e a avaliação das concentrações de PB em amostras de alimentos, sobras e fezes foi feita pelo método de Kjeldhal (AOAC, 1990). As estatísticas descritivas para as variáveis avaliadas são expressas na Tabela 1.

O coeficiente de digestibilidade verdadeiro e a contribuição metabólica fecal foram estimados sob a pressuposição de as médias de tratamentos constituírem estimadores independentes e não-viesados das médias populacionais. Os dados levantados foram avaliados por meio de adaptação ao teste de entidade nutricional relatado por Lucas \& Smart (1959), que se baseia no ajustamento de regressão linear simples, segundo o modelo: 
$Y_{i}=\beta X_{i}+\alpha+\varepsilon_{i}$

(1); em que: $Y_{i}=P B$ aparentemente retida ou digerida $(\mathrm{g} / \mathrm{dia})$; $\mathrm{X}_{\mathrm{i}}=\mathrm{PB}$ consumida $(\mathrm{g} / \mathrm{dia}) ; \beta=$ coeficiente de digestibilidade verdadeiro da $\mathrm{PB} ; \alpha=\mathrm{PB}$ metabólica fecal $(\mathrm{g} / \mathrm{dia}) ; \mathrm{e} \varepsilon_{\mathrm{i}}=$ erro aleatório, não-observável, pressuposto $\operatorname{NID}\left(0 ; \sigma^{2}\right)$.

Para que o componente químico do alimento/dieta seja considerado entidade nutricional, validando-se, portanto, o processo de estimação, as seguintes restrições devem ser observadas (Lucas \& Smart, 1959):

$0 \leq \hat{\beta} \leq 1$

$\hat{\alpha} \leq 0$

Em decorrência da possível diferença entre as categorias animais avaliadas, inseriu-se à equação (1) um esquema de avaliação de identidade de modelos por meio de variável dummy (Draper \& Smith, 1966). Para estimação do erro puro, no entanto, introduziu-se controle da variação experimental em função da variabilidade inter-experimentos. Desta forma, redefiniu-se o modelo descrito em (1) como:

$Y_{i j k}=\beta_{1} X_{i j k}+\beta_{2} C_{i} X_{i j k}+\alpha_{1}+\alpha_{2} C_{i}+E_{(i) k}+\varepsilon_{i j k}$ em que: $Y_{i j k}=P B$ aparentemente digerida obtida na observação $\mathrm{j}$, proveniente do experimento k conduzido sobre a categoria animal i (g/dia); $\mathrm{X}_{\mathrm{ijk}}=\mathrm{PB}$ consumida na observação $\mathrm{j}$, proveniente do experimento $\mathrm{k}$ conduzido sobre a categoria animal $\mathrm{i} ; \mathrm{C}_{\mathrm{i}}=$ variável dummy referente à categoria animal $\mathrm{i}$, sendo $\mathrm{C}_{1}=0$ para animais em crescimento e terminação e $C_{2}=1$ para vacas em lactação; $\beta_{1}$ e $\beta_{2}=$ parâmetros para estimação do coeficiente de digestibilidade verdadeiro da PB; $\alpha_{1}$ e $\alpha_{2}=$ parâmetros para estimação da proteína metabólica fecal (g/dia); $\mathrm{E}_{(\mathrm{i}) \mathrm{k}}=$ efeito aleatório relativo ao experimento $\mathrm{k}$ aninhado à categoria animal i; e $\varepsilon_{\mathrm{ijk}}=$ erro aleatório, não-observável, pressuposto NID $\left(0 ; \sigma^{2}\right)$.

As observações relativas à $\mathrm{PB}$ aparentemente digerida foram obtidas por meio do produto entre o consumo e o coeficiente de digestibilidade aparente.

A partir das modificações propostas para o modelo (1), descritas em (4), definiram-se as restrições para a consideração de entidade nutricional:

$0 \leq \hat{\beta}_{1}+\hat{\beta}_{2} \cdot C_{i} \leq 1$

$\hat{\alpha}_{1}+\hat{\alpha}_{2} \cdot C_{i} \leq 0$

Para validação do modelo desenvolvido a partir do coeficiente de digestibilidade verdadeiro e da contribuição metabólica fecal, foram utilizados dados obtidos em dois experimentos conduzidos com vacas em lactação (Oliveira, 2005; Pina et al., 2006) e dois conduzidos com bovinos em crescimento e terminação (Silva, 2004; Detmann et al., 2005b, 2005c).

Nos experimentos conduzidos por Oliveira (2005) e Pina et al. (2006), foram utilizadas 12 vacas lactantes, distri- buídas segundo delineamento em quadrado latino 4 x 4, com agrupamento de três quadrados, definidos em função da dimensão do período após o parto, totalizando 48 observações em cada experimento. Os animais foram manejados em baias individuais, em sistema de confinamento do tipo tie stall, sendo alimentadosad libitum duas vezes ao dia, logo após as ordenhas.

Os animais utilizados no experimento realizado por Oliveira (2005) foram alimentados com quatro dietas à base de: silagem de milho, com $40 \%$ de concentrado e $13,33 \%$ de PB; cana-de-açúcar, com $60 \%$ de concentrado e $14,12 \%$ de PB; cana-de-açúcar, com $60 \%$ de concentrado, incluindo $10 \%$ de casca de café, com 14,09\% de PB; cana-de-açúcar, com $60 \%$ de concentrado, incluindo $30 \%$ de casca de soja, com $14,16 \%$ de PB.

No experimento conduzido por Pina et al. (2006), foram avaliadas quatro dietas com $40 \%$ de concentrado, com base na MS, formuladas com diferentes fontes protéicas: farelo de soja, farelo de algodão $38 \%$, farelo de algodão $28 \%$ e uréia:sulfato de amônia, apresentando 14,71; 15,37; 14,65 e $14,62 \%$ de $\mathrm{PB}$, com base na MS, respectivamente.

No experimento conduzido por Silva (2004), foram utilizados quatro novilhos com grau de sangue predominantemente Holandês e peso médio de $320 \mathrm{~kg}$. O experimento foi conduzido em cinco períodos de 15 dias e os animais foram mantidos em confinamento em baias individuais, totalizando 20 observações. A dieta oferecida foi composta exclusivamente de capim-elefante, fornecido, em média, aos 33, 48, 63, 78 e 93 dias de rebrotação, com teores médios de 9,45; 5,61; 4,51; 2,56; e 2,45\% de PB, com base na MS. Em cada período experimental, o capim fornecido aos animais apresentava-se em um único período de rebrotação. Nos experimentos conduzidos por Detmann et al. (2005b; 2005c), foram utilizados cinco novilhos mestiços Holandês x Zebu (peso médio de $304 \mathrm{~kg}$ ), mantidos em pastagem de Brachiaria decumbens durante o período de transição entre as épocas seca e chuvosa. Foram avaliados suplementos constituídos por milho em grão, soja integral, uréia, sulfato de amônia e mistura mineral, fornecidos na quantidade de $4 \mathrm{~kg} /$ animal/dia, apresentando níveis de 12, 16, 20 e 24\% de PB, além de um tratamento controle, sem suplementação. Os experimentos foram conduzidos em delineamento quadrado latino 4 x 4, englobando somente os tratamentos com suplementação. $\mathrm{O}$ tratamento controle foi mantido fixo em um único animal, não pertencendo ao delineamento experimental, sendo utilizado como medida de comparação descritiva. Em termos médios, observaram-se nas dietas totais os níveis de 10,2; 12,0; 13,$3 ; 15,0$ e $16,9 \%$ de PB para os tratamentos controle e suplementos, na mesma ordem definida anteriormente. 
Para a avaliação estatística, os dados para ambas as categorias animais foram submetidos conjuntamente ao ajustamento, de forma independente aos efeitos de experimento e tratamentos, de modelo de regressão linear simples de valores observados (variável dependente) sobre valores preditos (variável independente), sendo os testes estatísticos conduzidos sob as seguintes hipóteses:

$$
\begin{array}{ll}
H_{0}: \beta_{0}=0 & H_{0}: \beta_{1}=1 \\
H_{a}: \beta_{0} \neq 0 & H_{a}: \beta_{1} \neq 1
\end{array}
$$

No caso de não-rejeição de ambas as hipóteses de nulidade, concluiu-se pela similaridade entre valores preditos e observados.

Todos os procedimentos estatísticos descritos neste trabalho foram realizados por meio do programa SAS (Littell et al., 1991), adotando-se 0,05 como nível crítico de probabilidade para o erro tipo I.

\section{Resultados e Discussão}

As bases teóricas adotadas para o desenvolvimento do modelo foram adaptadas às proposições de Blaxter \& Mitchell (1948) e Lucas (1960). Após a ingestão e digestão, resume-se a massa aparentemente não-digerida de compostos nitrogenados como:

$P B f=P B i+P B m+P B e$

em que: $\mathrm{PBf}=$ proteína bruta fecal $(\mathrm{g} / \mathrm{dia}) ; \mathrm{PBi}=$ proteína bruta verdadeiramente indigerida $(\mathrm{g} / \mathrm{dia}) ; \mathrm{PBm}=$ proteína bruta metabólica $(\mathrm{g} / \mathrm{dia}) ;$ e $\mathrm{PBe}=$ proteína bruta endógena (g/dia).

A proteína bruta metabólica foi definida como a porção dos compostos nitrogenados fecais proveniente de secreções do trato digestivo (Lucas, 1960) acrescida de matéria microbiana (Van Soest, 1994). Por outro lado, a PB endógena correspondeu à fração dos compostos nitrogenados fecais advinda da excreção de "restos" metabólicos pelas células do trato gastrintestinal (Lucas, 1960).

A partir dessas definições, relacionou-se a identidade exposta em (7) ao consumo diário de $\mathrm{PB}$ :

$$
\begin{aligned}
& P B c-P B f=P B c-(P B i+P B m+P B e) \\
& P B a r=P B c-P B i-P B m-P B e \\
& \frac{P B a r}{P B c}=\frac{P B c-P B i-P B m-P B e}{P B c} \\
& D a_{P B}=1-\frac{P B i}{P B c}-\frac{P B m}{P B c}-\frac{P B e}{P B c}
\end{aligned}
$$

em que: $\mathrm{PBc}=$ proteína bruta consumida $(\mathrm{g} / \mathrm{dia}) ; \mathrm{PBar}=$ proteína bruta aparentemente retida ou digerida ( $\mathrm{g} / \mathrm{dia})$; $\mathrm{Da}_{\mathrm{PB}}=$ coeficiente de digestibilidade aparente da PB; e PBf, $\mathrm{PBi}, \mathrm{PBm}, \mathrm{PBe}=$ como definidos anteriormente.
Em adaptação às proposições de Blaxter \& Mitchell (1948), pode-se afirmar que a contribuição endógena da PB pode ser representada como uma função matemática proporcional à massa metabólica do animal:

$\frac{P B e}{P B C}=\frac{\varepsilon \cdot P^{\frac{3}{4}}}{P B C}=\frac{\varepsilon}{P B c} \cdot P^{\frac{3}{4}}$

em que: $\mathrm{P}=$ massa do animal $(\mathrm{g}) ; \varepsilon=$ constante relacionada à liberação endógena de $\mathrm{PB}$ no trato gastrintestinal por unidade de massa metabólica $\left(\mathrm{g} / \mathrm{g} \times \mathrm{dia}^{-1}\right)$; e $\mathrm{PBe}$ e $\mathrm{PBc}=$ como definidos anteriormente.

A razão $\varepsilon / \mathrm{PBc}$, expressa em (9), somente poderia ser considerada significativa caso o consumo de PB assumisse valores extremamente pequenos (Lucas, 1960), possivelmente em níveis de alimentação abaixo da mantença. Assim, em condições normais de alimentação (mantença ou produção), ter-se-ia:

$\lim _{P B C \rightarrow P B^{\circ} c} \frac{\varepsilon}{P B C} \cdot P^{\frac{3}{4}}=0$

em que: $\mathrm{PB}^{\circ} \mathrm{c}=$ consumo de $\mathrm{PB}$ em condições normais de alimentação (g/dia); e $\mathrm{PBc}, \varepsilon$ e $\mathrm{P}=$ como definidos anteriormente.

Desta forma, a equação (8d) seria reescrita como:

$$
\begin{aligned}
& D a_{\mathbf{P} B}=\left(1-\frac{P B i}{P B C}\right)-\frac{P B m}{P B C} \\
& D a_{P B}=\left(1-I v_{P B}\right)-\frac{P B m}{P B C} \\
& D a_{P B}=D v_{P B}-\frac{P B m}{P B C}
\end{aligned}
$$

em que: $\mathrm{Iv}_{\mathrm{PB}}=$ coeficiente de indigestibilidade verdadeiro da $\mathrm{PB} ; \mathrm{Dv}_{\mathrm{PB}}=$ coeficiente de digestibilidade verdadeiro da $\mathrm{PB}$; e $\mathrm{Da}_{\mathrm{PB}}$, PBi, PBc e PBm = como definidos anteriormente.

Multiplicando-se ambos os termos da equação (11c) pelo consumo de $\mathrm{PB}$, obteve-se:

$P B c \cdot D a_{P B}=P B c \cdot D v_{P B}-P B m$

Derivando-se (12) em função do consumo de PB, encontrou-se:

$$
\frac{d\left(P B c \cdot D a_{P B}\right)}{d P B c}=D v_{P B}-\frac{d P B m}{d P B C}
$$

Dessa forma, a derivada expressa em (13), a qual representa o coeficiente de digestibilidade aparente da PB, pode ser representada por dois diferentes componentes: o primeiro é representado pelo coeficiente de digestibilidade verdadeiro constante da $\mathrm{PB}$ e o segundo, por uma porção metabólica, diferenciada pela massa de PB ingerida. 
Convertendo-se a equação (13) para a base percentual dietética, obteve-se:

$$
\begin{aligned}
& P B(\%) \cdot D a_{P B}=P B(\%) \cdot D v_{P B}-C M_{P B}(\%) \\
& P B_{a d}(\%)=P B_{v d}(\%)-C M_{P B}(\%)
\end{aligned}
$$

em que: $\mathrm{PB}(\%)=$ percentual dietético de $\mathrm{PB}$, com base na MS; $\mathrm{CM}_{\mathrm{PB}}(\%)$ = contribuição metabólica de $\mathrm{PB}$ como percentual da MS dietética; $\mathrm{PB}_{\mathrm{ad}}(\%)$ = nível dietético de $\mathrm{PB}$ aparentemente digestível, como percentual da matéria seca; $\mathrm{PB}_{\mathrm{vd}}(\%)$ = nível dietético de PB verdadeiramente digestível, como percentual da MS.

Na estimação de parâmetros e estruturação de equações, não foram verificados efeitos significativos de categoria animal sobre o coeficiente de inclinação da relação entre $\mathrm{PB}$ consumida e aparentemente retida $(\mathrm{P}>0,06)$, o que reflete o fato de a digestibilidade verdadeira deste componente, representada pelo coeficiente de inclinação expresso em (4), manter-se constante, independentemente da categoria animal, como descrito pela equação:

$$
P B_{v d}(\%)=0,7845 \cdot P B(\%)
$$

em que: $0,7845=$ estimativa do coeficiente de digestibilidade verdadeiro da $\mathrm{PB}, \operatorname{com} \operatorname{IC}(\beta)_{95 \%}$ : $[0,7565 \leq b \leq 0,8125]$; sendo os demais itens definidos anteriormente.

A acurácia dessa estimativa pode ser confirmada pela alta agregação dos pontos referentes às informações do banco de dados construído neste estudo para ambas as categorias animais avaliadas $\left(R^{2}=0,9964\right)$, mesmo com a adoção de um coeficiente de inclinação conjunto (Figuras 1 e 2).

Segundo o sistema de equações somativas adotado pelo NRC (2001), a obtenção do nível dietético de PB digestível de um alimento ou de uma dieta baseia-se na relação entre os compostos nitrogenados insolúveis em detergente ácido (NIDA) e o teor total de compostos nitrogenados, sob a pressuposição de os primeiros apresentarem indisponibilidade verdadeira constante para fontes de alimentos concentrados e volumosos (Weiss et al., 1992). Contudo, em estudo recente sobre alimentos produzidos em condições tropicais, verificou-se total falta de associação entre o teor de NIDA e a disponibilidade protéica potencial (Detmann et al., 2004b), o que indica que essa relação seja a possível causa da discrepância entre valores observados e preditos por meio do sistema somativo adotado pelo NRC (2001) em condições brasileiras (Campos, 2004; Oliveira, 2005; Pina, 2005).

Por outro lado, a estimativa obtida para o coeficiente de digestibilidade verdadeiro (Equação 15) mostrou-se inferior a valores preconizados em condições não-tropicais, normalmente superiores a 0,9 (Van Soest, 1994). Essas estimativas estão, em muitos casos, associadas à disponi-

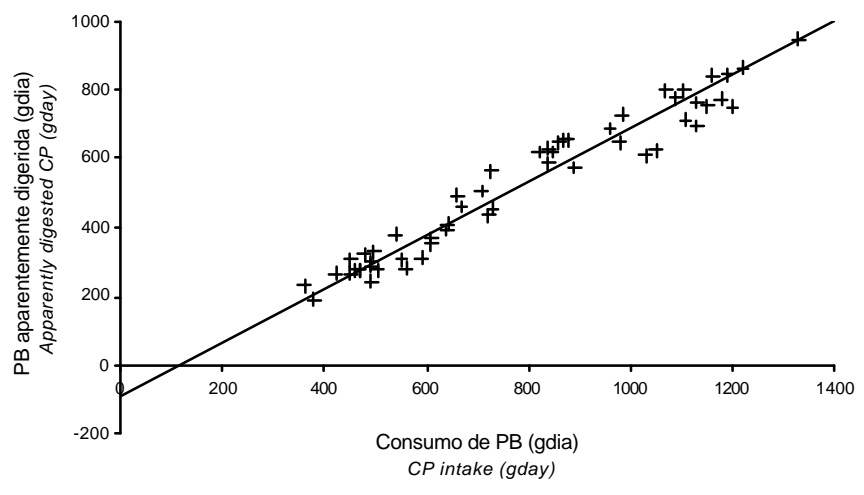

Figura 1 - Relação consumo x quantidade aparentemente digerida de $\mathrm{PB}$ em bovinos em crescimento e terminação (a linha de teṇdência corresponde à reta de quadrados mínimos: $\hat{\mathrm{Y}}=-92,3+0,7845 \mathrm{X} ; \mathrm{R}^{2}=0,9964$ ).

Figure 1 - Relationship between intake and apparently digested $C P$ in growing and finishing cattle (the trend line corresponds to the least squares straight line: $\left.\hat{\mathrm{Y}}=-92.3+0.7845 X ; R^{2}=0.9964\right)$.

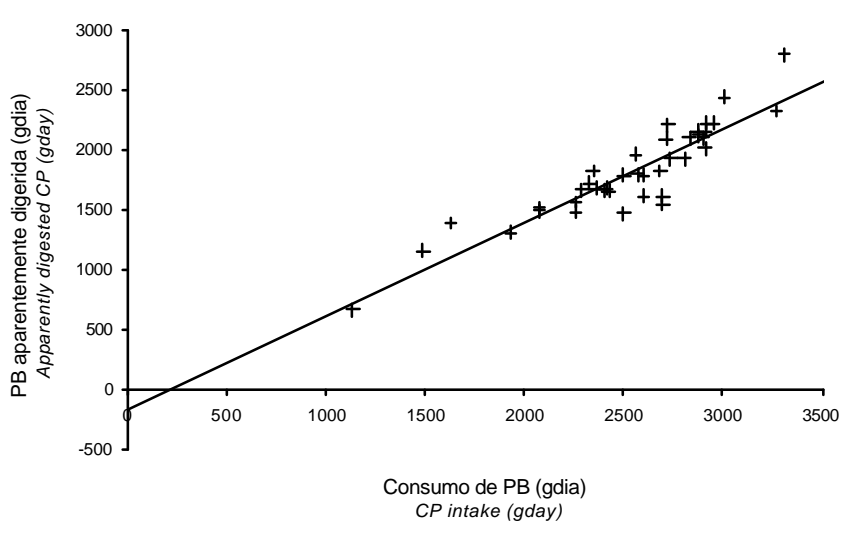

Figura 2 - Relação consumo x quantidade aparentemente digerida de PB em vacas em lactação (a linha de tendência corresponde à reta de quadrados mínimos. $\left.\hat{\mathrm{Y}}=-169,8+0,7845 \mathrm{X} ; \mathrm{R}^{2}=0,9964\right)$.

Figure 2 - Relationship between intake and apparently digested crude protein in lactating cows (the trend line corresponds to the least squares straight line: $\left.\hat{\mathrm{Y}}=-169.8+0.7845 X ; R^{2}=0.9964\right)$.

bilidade de proteínas do conteúdo celular vegetal. Em condições tropicais, porções significativas dos compostos nitrogenados totais estão associadas à parede celular ve getal (Malafaia et al., 1997; Cabral et al., 2000; Henriques, 2004), as quais apresentam disponibilidade efetiva e potencial inferiores quando comparadas às frações nitrogenadas solúveis em meio aquoso (Sniffen et al., 1992), justificando a dimensão da estimativa obtida neste trabalho.

Em contrapartida à similaridade observada para o coeficiente de digestibilidade verdadeiro, verificou-se efeito significativo $(\mathrm{P}<0,01)$ de categoria animal sobre a excreção 
de PB metabólica, cujas estimativas obtidas diretamente pelo modelo descrito em (4) foram de 92,3 e 169,8 g/dia, para bovinos em crescimento e terminação e vacas em lactação, respectivamente (Figuras 1 e 2). Ressalta-se que as estimativas obtidas para o coeficiente de digestibilidade verdadeiro e as contribuições metabólicas enquadraram-se nas restrições impostas em (5) e (6), garantindo o status de entidade nutricional à $\mathrm{PB}$ (Lucas \& Smart, 1959) e suportando os métodos de estimação adotados neste trabalho.

A superioridade da fração metabólica da $\mathrm{PB}$ em vacas em lactação, em comparação a animais em crescimento e terminação $(\mathrm{P}<0,01)$ (Figuras 1 e 2), justifica-se por sua relação diretamente proporcional ao consumo de PB (Lucas, 1960), como evidenciado pelos dados expressos na Tabela 1.

De outra forma, a verificação de um coeficiente de digestibilidade verdadeiro constante e independente da categoria animal, associado à contribuição metabólica diferenciada em função do consumo de PB, converge com exatidão às pressuposições teóricas sumariadas na equação (13), garantindo a validade do modelo proposto neste trabalho.

Com vistas à estimação do teor de PB aparentemente digestível (parâmetro base à proposição deste trabalho), o qual constitui componente direto do teor de NDT da dieta, procedeu-se à conversão das estimativas de PB metabólica (g/dia), em função do teor protéico dietético para cada valor integrante do banco de dados, utilizando-se a equação:

$$
\begin{aligned}
& C M_{P B}(\%)=\frac{P B_{v d}-P B a r}{P B C} \cdot P B(\%) \\
& C M_{P B}(\%)=\frac{0,7845 \cdot P B c-D a_{P B} \cdot P B C}{P B C} \cdot P B(\%) \\
& C M_{P B}(\%)=\left(0,7845-D a_{P B}\right) \cdot P B(\%)
\end{aligned}
$$

sendo todos os componentes definidos anteriormente.

A avaliação dos resultados produzidos via equação (16c) para cada categoria animal indicou não haver relação entre a contribuição metabólica percentual e o nível dietético de $\mathrm{PB}(\mathrm{P}>0,42)$, permitindo-se a representação dessa fração por valores constantes, conforme a seguir:

$$
P B_{a d}(\%)=0,7845 \cdot P B(\%)-1,61
$$

(Bovinos em crescimento e terminação)

$(17 \mathrm{a})$

$$
P B_{a d}(\%)=0,7845 \cdot P B(\%)-0,97
$$

(Vacas em lactação)

em que: 1,61 e 0,97 = estimativas para a PB metabólica, como percentual da MS da dieta; sendo os demais termos definidos anteriormente.

A superioridade da fração metabólica de animais em crescimento e terminação observada nas equações (17a) e (17b) aparentemente contradiz a condição teórica de rela- ção proporcional direta consumo x proteína bruta metabólica do modelo adotado, verificada por meio das estimativas numéricas obtidas neste estudo. No entanto, de forma particular, o coeficiente de digestibilidade aparente da PB sofre, proporcionalmente, maior influência da porção metabólica à medida que o consumo protéico se torna menor (Van Soest, 1994), justificando o comportamento para a maior proporcionalidade da fração metabólica em bovinos em crescimento e terminação (Equação 17a).

Considerando as características do banco de dados utilizado neste estudo, ressalta-se que as estimativas obtidas a partir das equações (17a) e (17b) são aplicáveis a animais alimentados ad libitum, ou seja, em nível de produção. Segundo observações realizadas em condições nacionais, a relação entre as concentrações de NDT em dietas fornecidas em situações de produção e mantença (consumo restrito) aproxima-se de 0,95 (Costa et al., 2005), relação que possivelmente se projeta para cada um de seus componentes.

Segundo as relações obtidas neste trabalho (Figuras $1 \mathrm{e}$ 2), não se esperam alterações no coeficiente de digestibilidade verdadeiro da PB em função do nível de consumo, sendo essa diferenciação observada somente sobre a contribuição metabólica (Equação 13). Desta forma, com base no consumo médio de PB observado para cada categoria (Tabela 1) e na relação de digestibilidade nos níveis de produção e mantença relatada por Costa et al. (2005), obtiveram-se as estimativas do teor dietético de $\mathrm{PB}$ aparentemente digerido em condições de mantença $\left(\mathrm{PB}_{\mathrm{adm}}\right)$ por:

$P B_{\text {adm }}(\%)=0,7845 \cdot P B(\%)-1,17$

(Bovinos em crescimento e terminação)

(18a);

$P B_{\text {adm }}(\%)=0,7845 \cdot P B(\%)-0,43$

(Vacas)

As estimativas dos parâmetros de regressão associadas aos respectivos níveis descritivos de probabilidade para os testes de hipóteses são apresentadas na Tabela 2 .

Verificou-se a não-rejeição de ambas as hipóteses de nulidade avaliadas $(\mathrm{P}>0,20)$ (Tabela 2; Figura 3 ), demonstrando efetivamente a adequação do modelo proposto (Equação 13) e das equações estabelecidas para as categorias animais avaliadas (16a e 16b).

Embora a inspeção gráfica do comportamento dos dados (Figura 3) permita evidenciar certo nível de variação dos dados em torno da linha de equalidade ( $\mathrm{Y}=\mathrm{X})$, este nível de variação, no entanto, não causou discrepância significativa entre valores preditos e observados $(\mathrm{P}>0,20)$ (Tabela 2). Entende-se que esse comportamento advenha de variações no consumo total de PB inerentes a cada animal, o que implica diretamente em variações na porção metabólica 
Tabela 2 - Estimativas dos parâmetros da regressão e níveis descritivos de probabilidade para o erro tipo I para as relações entre valores preditos (variável independente) e observados (variável dependente) para os níveis dietéticos de PB aparentemente digestível

Table 2 - Estimation of regression parameters and descriptive levels of probability of type I error for the relationship between predicted (independent variable) and observed (dependent variable) values of the dietary levels of apparently digestible crude protein

\begin{tabular}{lcc}
\hline $\begin{array}{l}\text { Parâmetro } \\
\text { Parameter }\end{array}$ & $\begin{array}{c}\text { Estimativa } \\
\text { Estimate }\end{array}$ & $\begin{array}{c}\text { Valor-P } \\
\text { P value }\end{array}$ \\
\hline $\begin{array}{l}\text { Intercepto } \\
\text { Intercept }^{1}\end{array}$ & 0,3310 & 0,3483 \\
Coeficiente de inclinação $^{2}$ & 0,9542 & 0,2067 \\
Slope coefficient & & \\
$\mathrm{s}_{\mathrm{xy}}$ & 1,02 & \\
$\mathrm{r}^{2}$ & 0,8455 & \\
$\mathrm{n}$ & 136 & \\
\hline${ }^{1} \mathrm{H}_{0}: \beta_{0}=0 ; \mathrm{H}_{\mathrm{a}}: \beta_{0} \neq 0$. & & \\
${ }^{2} \mathrm{H}_{0}: \beta_{1}=1 ; \mathrm{H}_{\mathrm{a}}: \beta_{1} \neq 1$. & & \\
& &
\end{tabular}

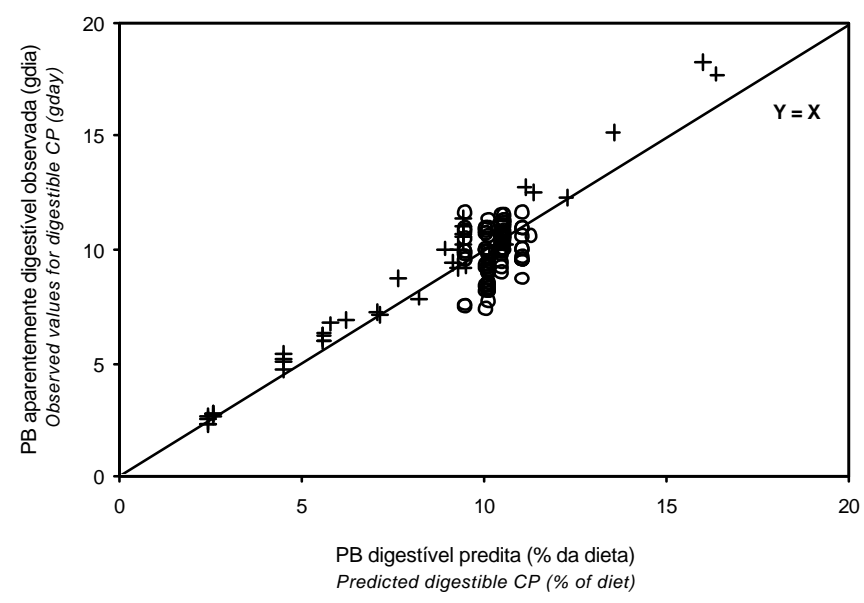

Figura 3 - Relação entre valores preditos e observados para os teores de PB digestível na dieta $(+=$ bovinos em crescimento e terminação; 0 = vacas em lactação).

Figure 3 - Relationship between predicted and observed values for digestible $\mathrm{CP}$ diet (+ = growing and finishing cattle; $\mathrm{O}=$ lactating cows).

fecal (Equação 13). Como as equações propostas são baseadas em valores médios (16a e 16b), cujo conjunto de dados empregado para estimação não permitiu evidenciar relações $(\mathrm{P}>0,42)$ com o nível dietético de $\mathrm{PB}$, essas variações mostram-se pouco relevantes e não-comprometedoras ao processo de estimação.

A acurácia obtida pelo modelo proposto neste trabalho evidencia sua capacidade preditiva do teor dietético de PB digestível em alimentos produzidos em condições tropicais, podendo agregar maior exatidão nas estimativas do teor de NDT dietético utilizando-se a composição química dos alimentos.

\section{Conclusões}

A estimação da fração digestível da proteína bruta dietética sob os pressupostos de constância no coeficiente de digestibilidade verdadeiro e diferenciação da contribuição metabólica em função do nível de consumo em bovinos mostra-se acurada para alimentos/dietas produzidos em condições tropicais.

Os modelos propostos neste estudo poderão ampliar a acurácia do processo de predição energética via nutrientes digestíveis totais utilizando-se a composição química dos alimentos.

\section{Literatura Citada}

ASSIS, A.J.; CAMPOS, J.M.S.; VALADARES FILHO, S.C. et al. Polpa cítrica em dietas de vacas em lactação. 1. Consumo de nutrientes, produção e composição do leite. Revista Brasileira de Zootecnia, v.33, n.1, p.242-250, 2004a.

ASSIS, A.J.; CAMPOS, J.M.S.; QUEIROZ, A.C. et al. Polpa cítrica em dietas de vacas em lactação. 2. Digestibilidade dos nutrientes em dois períodos de coleta de fezes, $\mathrm{pH}$ e nitrogênio amoniacal do líquido ruminal. Revista Brasileira de Zootecnia, v.33, n.1, p.251-257, 2004b.

ASSOCIATION OF OFFICIAL ANALYTICAL CHEMISTRY AOAC. Official methods of analysis. 15 ed. Arlington: AOAC International, 1990. 1117p.

BLAXTER, K.L.; MITCHELL, H.H. The factorization of the protein requeriments of ruminants and of the protein values of feeds, with particular reference to the significance of metabolic fecal nitrogen. Journal of Animal Science, v.7, n.2, p.351372, 1948.

CABRAL, L.S.; VALADARES FILHO, S.C.V.; MALAFAIA, P.A.M. et al. Frações protéicas de alimentos tropicais e suas taxas de digestão estimadas pela incubação com proteases ruminais. Revista Brasileira de Zootecnia, v.29, n.6, p.2316-2324, 2000 (supl. 2).

CAMPOS, P.R.S.S. Estimativas do valor energético de alguns volumosos e da digestibilidade da fibra em detergente neutro em ovinos. Viçosa, MG: Universidade Federal de Viçosa, 2004. 67p. Dissertação (Mestrado em Zootecnia) - Universidade Federal de Viçosa, 2004.

CARDOSO, R.C.; VALADARES FILHO, S.C.; COELHO DA SILVA, J.F. et al. Consumo e digestibilidades aparentes totais e parciais de rações contendo diferentes níveis de concentrado, em novilhos F1 Limousin x Nelore. Revista Brasileira de Zootecnia, v.29, n.6, p.1832-1843, 2000.

CARVALHO, A.U.; VALADARES FILHO, S.C.; LEÃO, M.I. et al. Níveis de concentrado em dietas de zebuínos. 1. Consumo e digestibilidade aparente. Revista Brasileira de Zootecnia, v.26, n.5, p.986-995, 1997.

CHIZZOTTI, M.L.; VALADARES FILHO, S.C.; LEÃO, M.I.et al. Casca de algodão em substituição parcial à silagem de capimelefante para novilhos. 1. Consumo, degradabilidade e digestibilidade total e parcial. Revista Brasileira de Zootecnia, v.34, n.6, p.2093-2102, 2005.

CONRAD, H.R.; WEISS, W.P.; ODWONGO, W.O. et al. Estimating net energy lactation from components of cell solubles and cell walls. Journal of Dairy Science, v.67, n.2, p.427-436, 1984.

COSTA, M.A.L; VALADARES FILHO, S.C.; VALADARES, R.F.D. et al. Validação das equações do NRC (2001) para predição do valor energético de alimentos em condições brasileiras. Revista Brasileira de Zootecnia, v.34, n.1, p.280-287, 2005. 
DETMANN, E.; ZERVOUDAKIS, J.T.; CABRAL, L.S. et al. Validação de equações preditivas da fração indigestível da fibra em detergente neutro em gramíneas tropicais. Revista Brasileira de Zootecnia, v.33, n.6, p.1866-1875, 2004a (supl. 1).

DETMANN, E.; CLIPES, R.C.; COELHO DA SILVA, J.F. et al. Avaliação da proteína insolúvel em detergente ácido como estimador da fração protéica indegradável no rúmen em forragens tropicais. In: REUNIÃO ANUAL DA SOCIEDADE BRASILEIRA DE ZOOTECNIA, 41., 2004, Campo Grande. Anais... Campo Grande: Sociedade Brasileira de Zootecnia, 2004b (CD-ROM).

DETMANN, E.; PAULINO, M.F.; CABRAL, L.S. et al. Simulação e validação de parâmetros da cinética digestiva em novilhos mestiços suplementados a pasto por intermédio de sistema in vitro de produção de gases. Revista Brasileira de Zootecnia, v.34, n.6, p.2112-2122, 2005a.

DETMANN, E.; PAULINO, M.F.; CECON, P.R. et al. Níveis de proteína em suplementos para terminação de bovinos em pastejo durante o período de transição seca/águas: consumo voluntário e trânsito de partículas. Revista Brasileira de Zootecnia, v.34, n.3, p.1371-1379, 2005b.

DETMANN, E.; PAULINO, M.F.; VALADARES FILHO, S.C. et al. Níveis de proteína em suplementos para terminação de bovinos em pastejo durante o período de transição seca/águas: digestibilidade aparente e parâmetros do metabolismo ruminal e dos compostos nitrogenados. Revista Brasileira de Zootecnia, v.34, n.4, p.1380-1391, 2005c.

DIAS, H.C.; VALADARES FILHO, S.C.; COELHO DA SILVA, J.F. et al. Consumo e digestões totais e parciais em novilhos F1 limousin $\mathrm{x}$ nelore alimentados com dietas contendo cinco níveis de concentrado. Revista Brasileira de Zootecnia, v.29, n.2, p.545-554, 2000

DRAPER, N.; SMITH, H. Applied regression analysis. New York: John Willey \& Sons, 1966. 407p.

HENRIQUES, L.T. Frações de carboidratos e compostos nitrogenados e parâmetros da cinética de degradação ruminal dos carboidratos de quatro gramíneas tropicais em diferentes idades de corte e doses de adubação nitrogenada. Campos dos Goytacazes: Universidade Estadual do Norte Fluminense, 2004. 66p. Tese (Doutorado em Produção Animal) - Universidade Estadual do Norte Fluminense, 2004.

ÍTAVO, L.C.V.; VALADARES FILHO, S.C.; SILVA, F.F. et al. Níveis de concentrado e proteína bruta na dieta de bovinos nelore nas fase de recria e terminação: consumo e digestibilidade. Revista Brasileira de Zootecnia, v.31, n.2, p.1033-1041, 2002 (supl.).

LADEIRA, M.M.; VALADARES FILHO, S.C.; COELHO DA SILVA, J.F. et al. Consumo e digestibilidades aparentes totais e parciais de dietas contendo diferentes níveis de concentrado em novilhos nelore. Revista Brasileira de Zootecnia, v.28, n.2, p.395403, 1999.

LEÃO, M.I. Metodologias de coletas de digestas omasal e abomasal em novilhos submetidos a três níveis de ingestão: consumo, digestibilidade e produção microbiana. Belo Horizonte: Universidade Federal de Minas Gerais, 2002. 57p. Tese (Doutorado em Ciência Animal) - Universidade Federal de Minas Gerais, 2002.

LITTELL, R.C.; FREUND, R.J.; SPECTOR, P.C.SAS system for linear models. Cary: SAS Intitute Inc., 1991. 329p.

LUCAS, H.L. Relations between apparent digestibility and the composition of feed and feces. 1. A quantitative theory. Raleigh: North Caroline State College, 1960. 55p. (Technical Report).

LUCAS, H.L.; SMART, W.W.G. Chemical composition and the digestibility of forages. In: PASTURE AND CROP IMPROVEMENT CONFERENCE, 16., 1959, Mississipi. Proceedings... Mississipi: Mississipi State University, 1959. p.23-26.
MAGALHÃES, K.A. Níveis de uréia ou casca de algodão na alimentação de novilhos de origem leiteira em confinamento. Viçosa, MG: Universidade Federal de Viçosa, 2003. 89p. Dissertação (Mestrado em Zootecnia) - Universidade Federal de Viçosa, 2003.

MALAFAIA, P.A.M.; VALADARES FILHO, S.C.; COELHO DA SILVA, J.F. et al. Sebo bovino em rações para vacas em lactação. 1. Consumo dos nutrientes, produção e composição do leite. Revista da Sociedade Brasileira de Zootecnia, v.25, p.153163, 1996a.

MALAFAIA, P.A.M.; VALADARES FILHO, S.C.; COELHO DA SILVA, J.F. et al. Sebo bovino em rações para vacas em lactação. 2. Digestão total e parcial dos nutrientes. Revista da Sociedade Brasileira de Zootecnia, v.25, p.164-176, 1996 b.

MALAFAIA, P.A.M.; VALADARES FILHO, S.C.; VIEIRA, R.A.M et al. Determinação e cinética ruminal das frações protéicas de alguns alimentos para ruminantes. Revista Brasileira de Zootecnia, v.26, n.6, p.1243-1251, 1997.

MENDONÇA, S.S.; CAMPOS, J.M.S.; VALADARES FILHO, S.C. et al. Consumo, digestibilidade aparente, produção e composição do leite e variáveis ruminais em vacas leiteiras alimentadas com dietas à base de cana-de-açúcar. Revista Brasileira de Zootecnia, v.33, n.2, p.481-492, 2004.

MORA, P.J.G.; VALADARES FILHO, S.C.; LEÃO, M.I. et al. Digestibilidade aparente dos nutrientes e energia líquida da silagem de milho (Zea mays L.) para vacas lactantes. Revista da Sociedade Brasileira de Zootecnia, v.25, p.357-368, 1996a

MORA, P.J.G.; LEÃO, M.I.; VALADARES FILHO, S.C. et al. Grãos de soja em rações para vacas lactantes: consumo dos nutrientes, produção e composição do leite. Revista da Sociedade Brasileira de Zootecnia, v.25, p.369-381, 1996 b.

NATIONAL RESEARCH COUNCIL - NRC. Nutrient requirements of dairy cattle. 7.ed. Washington: Academic Press, 2001.381p

OLIVEIRA, A.S.; VALADARES, R.F.D.; VALADARES FILHO, S.C. et al. Consumo, digestibilidade aparente e composição do leite em vacas alimentadas com quatro níveis de compostos nitrogenados não-protéicos. Revista Brasileira de Zootecnia, v.30, n.4, p.1358-1366, 2001

OLIVEIRA, A.S. Casca de café ou casca de soja em substituição ao milho em dietas à base de cana-de-açúcar para vacas leiteiras. Viçosa, MG: Universidade Federal de Viçosa, 2005. 90p. Dissertação (Mestrado em Zootecnia) - Universidade Federal de Viçosa, 2005.

PEREIRA, M.L.A.; VALADARES FILHO, S.C.; VALADARES, R.F.D. et al. Consumo, digestibilidade aparente total, produção e composição do leite em vacas no terço inicial da lactação alimentadas com níveis crescentes de proteína bruta no concentrado. Revista Brasileira de Zootecnia, v.34, n.3, p.1029-1039, 2005.

PINA, D.S. Fontes de proteína para vacas em lactação. Viçosa, MG: Universidade Federal de Viçosa, 2005. 84p. Dissertação (Mestrado em Zootecnia) - Universidade Federal de Viçosa, 2005.

PINA, D.S.; VALADARES FILHO, S.C.; VALADARES, R.F.D. et al. Consumo e digestibilidade aparente total dos nutrientes, produção e composição do leite de vacas alimentadas com dietas contendo diferentes fontes de proteína. Revista Brasileira de Zootecnia, v.35, n.4, p.1543-1551, 2006.

RENNÓ, L.N. Consumo, digestibilidade total e parcial, produção microbiana, parâmetros ruminais e excreções de uréia e creatinina em novilhos alimentados co dietas contendo quatro níveis de uréia ou dois níveis de proteína. Viçosa, MG: Universidade Federal de Viçosa, 2003. 267p. Tese (Doutorado em Zootecnia) - Universidade Federal de Viçosa, 2003.

ROCHA JR., V.R.; VALADARES FILHO, S.C.; BORGES, A.M. et al. Estimativa do valor energético dos alimentos e validação das equações propostas pelo NRC (2001). Revista Brasileira de Zootecnia, v.32, n.2, p.480-490, 2003. 
SCHOFIELD, P.; PITT, R.E.; PELL, A.N. Kinetics of fiber digestion from in vitro gas production. Journal of Animal Science, v.72, n.11, p.2980-2991, 1994.

SILVA, P.A. Valor energético do capim-elefante em diferentes idades de rebrota e estimativa da digestibilidade in vivo da fibra em detergente neutro. Viçosa, MG: Universidade Federal de Viçosa, 2004. 72p. Dissertação (Mestrado em Zootecnia) - Universidade Federal de Viçosa, 2004.

SILVA, R.M.N.; VALADARES, R.F.D.; VALADARES FILHO, S.C. et al. Uréia para vacas em lactação. 1.Consumo, digestibilidade, produção e composição do leite. Revista Brasileira de Zootecnia, v.30, n.5, p.1639-1649, 2001.

SNIFFEN, C.J.; O'CONNOR, J.D.; Van SOEST, P.J. et al. A net carbohydrate and protein system for evaluating cattle diets: II.Carbohydrate and protein availability. Journal of Animal Science, v.70, n.11, p.3562-3577, 1992.

SOARES, C.A.; CAMPOS, J.M.S.; VALADARES FILHO, S.C. et al. Consumo, digestibilidade, produção e composição do leite de vacas leiteiras alimentadas com farelo de trigo. Revista Brasileira de Zootecnia, v.33, n.6, p.2161-2169, 2004 (supl. 2).

TIBO, G.C.; VALADARES FILHO, S.C.; VALADARES, R.F.D. et al. Níevis de concentrado em dietas de novilhos mestiços F1 Simental x Nelore. 1. Consumo e digestibilidades. Revista Brasileira de Zootecnia, v.29, n.3, p.910-920, 2000.

TILLEY, J.M.A.; TERRY, R.A. A two-stage technique for the in vitro digestion of forage crops. Journal of British Grassland Society, v.18, n.2, p.104-111, 1963.
VALADARES, R.F.D.; GONÇALVES, L.C.; RODRIGUEZ, N.M. et al. Níveis de proteína em dietas de bovinos. 1. Consumo e digestibidades aparentes e parciais Revista Brasileira de Zootecnia, v.26, n.6, p.1252-1258, 1997.

Van SOEST, P.J. Nutritional ecology of the ruminant. Ithaca: Cornell University Press, 1994. 476p.

VÉRAS, A.S.C.; VALADARES FILHO, S.C.; COELHO DA SILVA, J.F. et al. Consumo e digestibilidade aparente em bovinos Nelore, não-castrados, alimentados com rações contendo diferentes níveis de concentrado. Revista Brasileira de Zootecnia, v.29, n.6., p.2367-2378, 2000 (supl. 2).

VIEIRA, R.A.M.; PEREIRA, J.C.; MALAFAIA, P.A.M. et al. Simulação da dinâmica de nutrientes no trato gastrintestinal: aplicação e validação de um modelo matemático para bovinos a pasto. Revista Brasileira de Zootecnia, v.29, n.3, p.898909, 2000.

WEISS, W.P.; CONRAD, H.R.; St.PIERRE, N.R. A theroticallybased model for predicting total digestible nutrient values of forage and concentrates. Animal Feed Science and Technology, v.39, p.95-110, 1992. 